ScIDice

\section{Assessment of Noxious Gases Emission from Herbal and Conventional Cigarettes - A Comparative Study toward Health Promotion}

Research Article

Anmol Mathur ${ }^{1 *}$, Dr. Sushil Phansopkar ${ }^{2}$, Neelu Nawani ${ }^{3}$

${ }^{1}$ Associate Professor, Department Of Public Health Dentistry, Dr. D.Y PatilVidyapeeth Pune. Maharashtra India.

${ }^{2}$ Dental Surgeon, Pune Maharashtra, India.

${ }^{3}$ Professor and HeadMicrobial Diversity Research Centre, Dr D Y Patil Biotechnology and Bioinformatics Centre, Dr. D.Y Patil Vidyapeeth Pune. Maharashtra, India.

\title{
Abstract
}

Introduction: Smokers, who wish to stop smoking, are introduced to another equally harmful product, herbal cigarette in order to help with their withdrawal symptoms, which are presented as safe alternatives. Herbal and Conventional brands both release noxious gases whose level are not mentioned on the packaging such as carbon monoxide and nitric oxide.

Material and Methods: Smoke of seventeen cigarette brands belonging to conventional and herbal respectively were exposed to the sensor which reports the emission of gases in $\mathrm{ppm}$.

This process is being repeated twice in order to reduce the margin of error and eliminate bias.

The mean $\mathrm{CO}$ and $\mathrm{NO}$ values were calculated for the conventional, herbal and different length categories of the cigarette.

Results: Herbal cigarettes of $64 \mathrm{~mm}$ length emitted $5437 \mathrm{ppm}$ of $\mathrm{CO}$ whereas a cigarette of $84 \mathrm{~mm}$ length emitted $4042 \mathrm{ppm}$, and cigarette of $80 \mathrm{~mm}$ length produced $5470 \mathrm{ppm}$ of CO.

Conclusion: The authors conclude that considering the deleterious effects reported by $\mathrm{CO}$ and NO on the human body the multinational tobacco companies must be directed to mention the levels on the packaging. Herbal cigarettes should be validated by a competent authority prior to their use as an alternative to NRT. This health education approach to sensitise towards noxious gas emission can be of great use among beginners and young crowd, also the law can come into place to mention the $\mathrm{CO}$ levels on the packages of all the cigarettes in the market either herbal or conventional.

\section{Introduction}

Smoke emitted from Tobacco when burned is a multifaceted, dynamic and reactive combination containing around 5,000 chemicals. [1-3] It has been identified as a potent carcinogenic mixture which is undoubtedly the most substantial source of exposure towards toxic chemical causing diseases among the human race. $[4,5]$ WHO has estimated, that there are 5.4 million people losing life due to this preventable death caused by tobacco smoking around the world.[6] If this practice continues, it can be predicted that the deaths can reach to as high as, 10 million marks among smokers per year by the end of 2025.[7, 8]

The WHO Framework Convention on Tobacco Control (FCTC) issues a complete outline for global tobacco control efforts. The FCTC is responsible for all facets of tobacco control, including tobacco product regulation, advertising, health warnings, price and tax issues, illicit trade (smuggling) and programs for smoking cessation.

Due to the efforts of FCTC, in recent time the number of smokers who wish to stop smoking has increased.[9] However, many smokers who wished to stop smoking, use nicotine replacement therapy $[10,11]$ to help with withdrawal symptomsor are introduced to another equally harmful product herbal cigarette presented as herbal/non-smoking or safe alternatives.

Authors feel that this could be a marketing strategy of Tobacco Giants who are investing a huge amount in marketing their products and increasing their market share by perusing probable quitters back in the business. Herbal cigarette contains herbs, instead of tobacco leaves, as the raw material. However, the safety and chemical composition of herbal cigarette smoke have been scarcely studied.

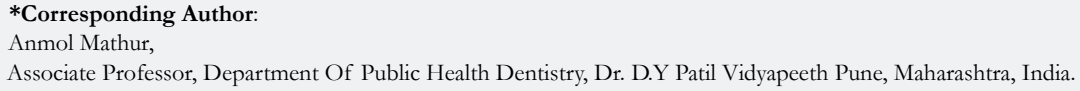

Citation: Anmol Mathur, Dr. Sushil Phansopkar, Neelu Nawani. Assessment of Noxious Gases Emission from Herbal and Conventional Cigarettes - A Comparative Study toward Health Promotion. Int J Dentistry Oral Sci. 2021;8(10):4719-4722. doi: http://dx.doi.org/10.19070/2377-8075-21000959

Copyright: Anmol Mathur ${ }^{\circ}$ 2021. This is an open-access article distributed under the terms of the Creative Commons Attribution License, which permits unrestricted use, distribution and reproduction in any medium, provided the original author and source are credited. 
Nevertheless, as yet, tobacco products are loosely regulated and largely exempt from any safety standards.

Carbon monoxide (CO) which is a poisonous, colourless and odourless killer gets emitted in tobacco-related smoke. The level of CO $[12,13]$ have been evaluated to correlate the number of cigarettes smoked per day and levels of CO in breath, which is a reliable indicator [14] and is preferred because of its non-invasive nature, easy procedure and better compliance.[15] The patient can definitely be made aware of the CO levels in the breath and has a high impact towards making people quit the habit.

When nitrogen is released during fuel combustion it combines with oxygen atoms to create nitric oxide (NO), this mainly impacts on respiratory conditions causing inflammation of the airways at high levels. Long term exposure can decrease lung function, increase the risk of respiratory conditions and increases the response to allergens.

However, no attempts till date have been made to find the $\mathrm{CO}$ and NO levels of conventional and herbal cigarettes available in the Indian market or even abroad to the best of our knowledge. This health education approach to sensitise towards noxious gas emission of their brand of cigarette can be of great use among beginners and young crowd who are the new targets of the tobacco industry, also the law can come into the place to mention the $\mathrm{CO}$ levels on the packages of all the cigarettes in the market either herbal or conventional.

\section{Materials And Methods}

In order to analyse the $\mathrm{CO}$ and $\mathrm{NO}$ content from the smoke of cigarettes, seventeen cigarette brands were shortlisted, these brand of cigarette were reported by the shopkeepers as maintaining maximum sales among conventional cigarette brands. The herbal options were two in number and based on convenience sampling as these brands were available in stores labelled as pure herbal products.

The conventional and herbal cigarettes were further classified on the basis of the length of each cigarette in $\mathrm{mm}$ what was mentioned on the packets. Broadly three lengths got to be classified as $84 \mathrm{~mm}, 80 \mathrm{~mm}$ and $64 \mathrm{~mm}$ in length.

The authors in the present survey wanted to measure the CO content without considering exhaled human breath content as this study attempts to bring forward the CO levels emitted by various cigarette and use these findings for educating people and bringing the attention of policymakers towards the effect of exposure of the $\mathrm{CO}$ from tobacco smoke.

Industrial $\mathrm{CO}$ analyser is the method used in the present survey of recording exact measurement of $\mathrm{CO}$ and $\mathrm{NO}$ among individually selected brands of cigarette, this machine is being used to precisely record and report any accidental leakage of the poisonous gases in industrial settings. The TESTO 350, is a rugged easyto-use exhaust gas analyser designed to meet the highest demands when it comes to carrying out precise industrial emission measurements and providing proper data administration. The Analysis Box can be operated with up to 6 gas sensors. The measurement is recorded in ppm and the slightest of the difference can be detected.

\section{Study design}

The measurement analysis was done with the highest accuracy which was completely based on the electronic readings given by the gas analyser, all of the findings were retested and the maximum emission and minimum emission were recorded in order to have consistent results and avoid bias. The calibration of the analyser and the entire set up was done before even initiating the survey. The smoke trap apparatus was designed in such a way that the cigarette has to be burned in the chamber which is attached to the smoke collection chamber, the sensor present in this chamber starts to provide the findings on the digital monitor of the TESTO 350 unit. The findings were recorded by a recorder that constantly monitors the readings and is blinded towards the brand of cigarette for which recordings are to be made. This process is being repeated for all 17 samples twice in order to reduce the margin of error and eliminate bias. The apparatus had to be cleaned after every cycle and the glass chambers had to be washed and left for drying.

\section{Statistics}

The mean $\mathrm{CO}$ and $\mathrm{NO}$ values were calculated for the conventional, herbal and different length categories of the cigarette, the $\mathrm{p}$ values with the help of Kruskal-Wallis Test Mann-Whitney U Test were calculated using SPSS version 21.

\section{Results And Discussion}

The present study is being conducted to identify the $\mathrm{CO}$ and NO emission levels from the conventional and herbal cigarettes, further the emission had to be compared according to the length of the cigarettes.

The CO is a poisonous gas, when inhaled from tobacco smoke it gets absorbed through the lungs and enters into the bloodstream and combines with haemoglobin to form carboxy-haemoglobin $(\mathrm{COHb})$, thereby reducing oxygen supply to the body tissues and organs. The CO remains in the blood for about 24 hours after inhalation of tobacco smoke, this $\mathrm{CO}$ present in exhaled air can be measured using a portable $\mathrm{CO}$ analyser.

The CO emission is clearly reported to be more in herbal brands of a cigarette when compared to conventional ones. $\mathrm{CO}$ emission is inversely proportional to the length of the cigarette with longer ones reporting minimum levels of CO. Herbal cigarettes of $64 \mathrm{~mm}$ length emitted $5437 \mathrm{ppm}$ of $\mathrm{CO}$ whereas a cigarette of $84 \mathrm{~mm}$ length emitted $4042 \mathrm{ppm}$ and cigarette of $80 \mathrm{~mm}$ length produced $5470 \mathrm{ppm}$ of CO.

There have been studies reporting the levels of exhaled CO among smokersaccording to the 'pack year' which is calculated on the basis of the number of cigarettes a person smokes (one pack each containing 20 cigarettes smoked per day for one year is one pack-year).[16] This has been made for the convenience of calculation and to have standardisation of all smokers for different duration and quantity. Consumption of tobacco has, therefore, been calculated in terms of "pack years" based on tobacco 
Table 1. Comparison of Mean Carbon Monoxide and Nitrous Oxide gas emission among conventional and herbal cigarette brands.

\begin{tabular}{|c|c|c|c|}
\hline Group & Units in ppm & Carbon Monoxide & Nitrous Oxide \\
\hline \multirow{2}{*}{$\begin{array}{c}\text { Conven- } \\
\text { tional }\end{array}$} & Mean & 4137.8 & 103.73 \\
\cline { 2 - 4 } & SD & 2250.74 & 29.31 \\
\hline \multirow{2}{*}{ Herbal } & Mean & 5256.5 & 95 \\
\cline { 2 - 4 } & SD & 74.24 & 22.63 \\
\hline \multirow{2}{*}{ Total } & Mean & 4269.41 & 102.71 \\
\cline { 2 - 4 } & SD & 2137.99 & 28.14 \\
\hline p valueb & & 0.51 & 0.69 \\
\hline
\end{tabular}

p value ${ }^{\beta}$

Table 1 determines the mean CO emission of cigarettes according to nature, herbal brands reported mean ppm of 5256(74.24) and conventional brands have a mean of $4137 \mathrm{ppm}$ of CO emission. NO gas emission reported mean $103 \mathrm{ppm}$ and mean $95 \mathrm{ppm}$ for conventional and herbal brands respectively.

Table 2. Comparison of Mean Carbon Monoxide and Nitrous Oxide gas emission according to cigarettes with different lengths.

\begin{tabular}{|c|c|c|c|}
\hline Length & Units in ppm & Carbon Monoxide & Nitrous Oxide \\
\hline \multirow{2}{*}{$84 \mathrm{~mm} \#$} & Mean & 3774.5 & 103.42 \\
\cline { 2 - 4 } & SD & 1715.15 & 23.44 \\
\hline \multirow{2}{*}{$80 \mathrm{~mm}^{*}$} & Mean & 5469 & 89 \\
\cline { 2 - 4 } & SD & 371.79 & 19.08 \\
\hline \multirow{2}{*}{$64 \mathrm{~mm}+$} & Mean & 5439.5 & 119 \\
\cline { 2 - 4 } & SD & 5523.21 & 69.29 \\
\hline p valued & & 0.36 & 0.53 \\
\hline
\end{tabular}

Table 2 presents the mean $\mathrm{CO}$ and NO emission from cigarettes according to the length in which they are marketed, length of 64 mm reported mean 5437 ppm of CO which reduced to mean $4041 \mathrm{ppm}$ for cigarette of $84 \mathrm{~mm}$ of length. NO emission is least reported among cigarette of $80 \mathrm{~mm}$ in length.

Figure 1. Carbon Monoxide Emission Level of all 15 conventional and 2 herbal cigarette brands individually.

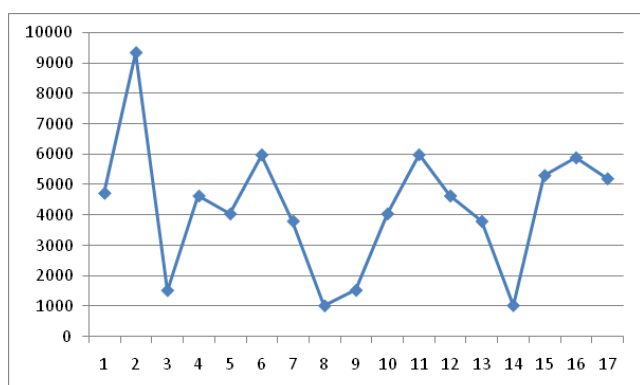

Figure 1 represents the individual emission level reported among every cigarette brand of Carbon Monoxide gas, the last two brand number 16 and 17 represent the herbal products.

Among the 17 brands used, 15 belong to the conventional category and 2 were herbal brands.

weight. Logically, "pack-years" cannot be calculated on the basis of the weight of tobacco; otherwise, "pack-years" would vary according to the brand of cigarettes as different brands have different weights. Thus, there appears to be no scientific basis for equating cigaretteon the basis of tobacco weight. In addition to this, most of the brands in India has ten cigarettes in one pack which compromises the "pack year" calculation and its validity. The health-related concern is also arising in such experiments where the sample is being selected on the basis of merit towards continuing the habit for such a long time and at high frequency. These experiments are dependent on the responses of the subject where the subject can have difficulty in remembering the events and incorporate recall bias which is another issue arising. Hence the authors selected a new process to check the emission levels from different brands of cigarettes.

Unfortunately, the tobacco brands are not liable to inform the emission levels of cigarettes although they emit noxious gases despite being labelled as "herbal".
The present study results can be used to educate the general people regarding the content of noxious gases present in the smoke of the concerned brand; they must be made aware that the alternative products proposed are not to be considered healthy alternatives at any cost.

In an interesting research conducted by university students of Alaska [17], it was revealed that cigarette smoke has a much higher $\mathrm{CO}$ concentration than does the exhaust from a clean, well-maintained vehicle. In fact, all of the cigarette measurements which were made gave CO mixing ratios of greater than $1.0 \%$, which is the usual "passing" value for cars that must have annual emission tests. Of the cars tested in this experiment, none exceeded the $1.0 \%$ level.

The exposure of $\mathrm{CO}$ concentrations can be well understood with the results of a study conducted to evaluate the impact of the smoking ban law in the city of Sao Paulo, Brazil, [18] on the CO concentration in restaurants, bars, night clubs and similar venues and in their workers. The average CO concentration measured in 
the city was lower than $1 \mathrm{ppm}$ during both pre-ban and post-ban periods. Smoking-free legislation reduced significantly the CO concentration in hospitality venues and in their workers, whether they smoke or not. These results clearly indicate the effect of $\mathrm{CO}$ levels in the atmosphere due to smoking.

This issue will raise the concern towards the second-hand smoke (SHS) or people who are exposed to cigarette smoke unwantedly, The results of the study where CO levels were monitored in 22 Polish pubs [19] also showed, that passive smoker can be exposed to very high $\mathrm{CO}$ concentration exceeding the WHO. The results presented in this article prove that passive smoking in public places like pubs might be a potential health risk because of breathing air with elevated levels of CO. Moreover, pubs' patrons and staff are a special group occupationally exposed to higher levels of $\mathrm{CO}$ for a long time.

The results from present survey indicate that $\mathrm{NO}$ emission from a conventional cigarette (103.7) is more than that of herbal brands with (95) mean ppm of emission.

Amount of $\mathrm{NO}$ in the cigarette smoke is of prime importance as it has been proposed by a literature review that inhaled NO from smoke may be able to increase nicotine absorption, which is responsible for smoking addiction. Since it has been shown that NO from smoke dilates pulmonary vessels in humans and animals $[20,21]$ the dilated pulmonary vessels allow the smoker to breathe deep and comfortably allowing the nicotine to reach in high concentration. In view of smoking addiction, animal studies have reported that NO contribute to nicotine dependence among rodents. [22, 23]

$\mathrm{CO}$ when emitted in public places with closed surroundings can have a serious effect on human beings, the attraction of haemoglobin towards $\mathrm{CO}$ is well understood and the reduction in oxygen-carrying capacity has been documented. Regarding NO it still remains unclear whether reducing the NO content in cigarette smoke may reduce nicotine absorption but its role in tobacco smoke addiction has been documented.

\section{Conclusion}

The findings of the current research can be used to draft the guidelines towards strict law implementation towards $\mathrm{CO} / \mathrm{NO}$ levels to be disclosed by the tobacco companies.

The authors conclude that considering the effects reported by $\mathrm{CO}$ and $\mathrm{NO}$ on the human body the multinational tobacco companies must be directed to mention the levels on the packaging. Herbal cigarettes should be validated by a competent authority prior to their use as an alternative to NRT.

\section{Acknowledgements}

We acknowledge the funding received from DPU Dr. D. Y. PatilVidyapeeth, Pune towards this research and we thank Dr. D. Y. Patil Biotechnology and Bioinformatics Institute for providing technical assistance in order to make data collection.

\section{References}

[1]. Hoffmann D, Hoffmann I. Letters to the editor, tobacco smoke components. Beiträge zur Tabakforschung/Contributions to Tobacco Research. 1998;18(1):49.

[2]. Thielen A, Klus H, Müller L. Tobacco smoke: unraveling a controversial subject. Exp Toxicol Pathol. 2008 Jun;60(2-3):141-56. Pubmed PMID: 18485684

[3]. Borgerding M, Klus H. Analysis of complex mixtures--cigarette smoke. Exp Toxicol Pathol. 2005 Jul;57 Suppl 1:43-73. Pubmed PMID: 16092717.

[4]. Fowles J, Dybing E. Application of toxicological risk assessment principles to the chemical constituents of cigarette smoke. Tob Control. 2003 Dec;12(4):424-30. Pubmed PMID: 14660781.

[5]. Ezzati M, Lopez AD. Estimates of global mortality attributable to smoking in 2000. Lancet. 2003 Sep 13;362(9387):847-52. Pubmed PMID: 13678970 .

[6]. World Health Organization. WHO report on the global tobacco epidemic: the MPOWER package. WHO report on the global tobacco epidemic: the MPOWER package. 2008.

[7]. Hatsukami DK, Stead LF, Gupta PC. Tobacco addiction. The Lancet. 2008 Jun 14; 371(9629): 2027-38.

[8]. Davis RM, Wakefield M, Amos A, Gupta PC. The Hitchhiker's Guide to Tobacco Control: a global assessment of harms, remedies, and controversies. Annu Rev Public Health. 2007;28:171-94.Pubmed PMID: 17367285.

[9]. WHO Report on the Global Tobacco Epidemic. 2019.

[10]. Hughes JR, Keely J, Naud S. Shape of the relapse curve and long-term abstinence among untreated smokers. Addiction. 2004 Jan;99(1):29-38. Pubmed PMID: 14678060.

[11]. Gourlay SG, Forbes A, Marriner T, Pethica D, McNeil JJ. Double blind trial of repeated treatment with transdermal nicotine for relapsed smokers. BMJ. 1995 Aug 5;311(7001):363-6. Pubmed PMID: 7640544.

[12]. Wald N, Idle M, Bailey A. Carboxyhaemoglobin levels and inhaling habits in cigarette smokers. Thorax. 1978 Apr;33(2):201-6. Pubmed PMID: 663879 .

[13]. Middleton ET, Morice AH. Breath carbon monoxide as an indication of smoking habit. Chest. 2000 Mar;117(3):758-63. Pubmed PMID: 10713003.

[14]. Jarvis MJ, Russell MA, Saloojee Y. Expired air carbon monoxide: a simple breath test of tobacco smoke intake. Br Med J. 1980 Aug 16;281(6238):4845. Pubmed PMID: 7427332.

[15]. Verhoeff AP, Van der Velde HC, Boleij JS, Lebret E, Brunekreef B. Detecting indoor $\mathrm{CO}$ exposure by measuring $\mathrm{CO}$ in exhaled breath. International archives of occupational and environmental health. 1983 Dec; 53(2): $167-$ 73.

[16]. Kumar R, Prakash S, Kushwah AS, Vijayan VK. Breath carbon monoxide concentration in cigarette and bidi smokers in India. Indian J Chest Dis Allied Sci. 2010 Jan-Mar; 52(1): 19-24. Pubmed PMID: 20364610.

[17]. Jaffe D, Chavasse L. Comapring the CO content of cigarette smoke and auto exhaust. Journal of College Science Teaching. 1999 Dec 1; 29(3): 172.

[18]. Issa JS, Abe TM, Pereira AC, Megid MC, Shimabukuro CE, Valentin LS, et al. The effect of Sao Paulo's smoke-free legislation on carbon monoxide concentration in hospitality venues and their workers. Tob Control. 2011 Mar;20(2):156-62. Pubmed PMID: 21109684.

[19]. Goniewicz MŁ, Czogała J, Kośmider L, Koszowski B, Zielińska-Danch W, Sobczak A. Exposure to carbon monoxide from second-hand tobacco smoke in Polish pubs. Cent Eur J Public Health. 2009 Dec;17(4):220-2. PMID: 20377053.

[20]. Alving K, Fornhem C, Lundberg JM. Pulmonary effects of endogenous and exogenous nitric oxide in the pig: relation to cigarette smoke inhalation. $\mathrm{Br}$ J Pharmacol. 1993 Oct;110(2):739-46. Pubmed PMID: 8242246.

[21]. Bennett MR. Apoptosis of vascular smooth muscle cells in vascular remodelling and atherosclerotic plaque rupture. Cardiovasc Res. 1999 Feb;41(2):361-8. Pubmed PMID: 10341835.

[22]. Adams ML, Cicero TJ. Nitric oxide mediates mecamylamine-and naloxoneprecipitated nicotine withdrawal. European journal of pharmacology. 1998 Mar 19; 345(2): R1-2.

[23]. Malin DH, Lake JR, Shenoi M, Upchurch TP, Johnson SC, Schweinle WE, et al. The nitric oxide synthesis inhibitor nitro-L-arginine (L-NNA) attenuates nicotine abstinence syndrome in the rat. Psychopharmacology. 1998 Dec; 140(3): 371-7. 